\title{
Ultra-processed family foods in Australia: nutrition claims, health claims and marketing techniques
}

\author{
Claire Elizabeth Pulker ${ }^{1, *}$, Jane Anne Scott ${ }^{1}$ and Christina Mary Pollard ${ }^{1,2}$ \\ ${ }^{1}$ School of Public Health, Curtin University, GPO Box U1987, Perth, WA 6845, Australia: ${ }^{2}$ Department of Health in \\ Western Australia, East Perth, WA, Australia
}

Submitted 8 September 2016: Final revision received 27 March 2017: Accepted 8 May 2017: First published online 17 July 2017

\begin{abstract}
Objective: To objectively evaluate voluntary nutrition and health claims and marketing techniques present on packaging of high-market-share ultra-processed foods (UPF) in Australia for their potential impact on public health.

Design: Cross-sectional.

Setting: Packaging information from five high-market-share food manufacturers and one retailer were obtained from supermarket and manufacturers' websites. Subjects: Ingredients lists for 215 UPF were examined for presence of added sugar. Packaging information was categorised using a taxonomy of nutrition and health information which included nutrition and health claims and five common food marketing techniques. Compliance of statements and claims with the Australia New Zealand Food Standards Code and with Health Star Ratings (HSR) were assessed for all products.

Results: Almost all UPF (95\%) contained added sugars described in thirty-four different ways; $55 \%$ of UPF displayed a HSR; $56 \%$ had nutrition claims (18\% were compliant with regulations); $25 \%$ had health claims (79\% were compliant); and $97 \%$ employed common food marketing techniques. Packaging of $47 \%$ of UPF was designed to appeal to children. UPF carried a mean of 1.5 health and nutrition claims (range 0-10) and 2.6 marketing techniques (range 0-5), and 45\% had $\mathrm{HSR} \leq 3 \cdot 0 / 5 \cdot 0$

Conclusions: Most UPF packaging featured nutrition and health statements or claims despite the high prevalence of added sugars and moderate HSR. The degree of inappropriate or inaccurate statements and claims present is concerning, particularly on packaging designed to appeal to children. Public policies to assist parents to select healthy family foods should address the quality and accuracy of information provided on UPF packaging.
\end{abstract}

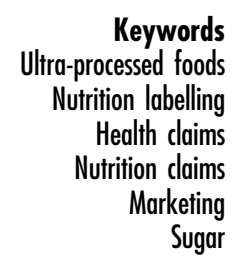

Packaging of foods and non-alcoholic beverages (referred to as 'food' hereafter) is an important marketing tool used by manufacturers to communicate product attributes to potential consumers ${ }^{(1)}$, with product claims a key feature $^{(2)}$. A large proportion of supermarket purchases are made on impulse and packaging has been shown to play a crucial role $^{(3)}$. Shoppers typically make these decisions after only a few seconds to consider food labels $^{(4)}$. The front of the package plays a vital role in capturing consumers' attention and influencing food preferences $^{(2,5)}$. Packaging design can also influence consumer perceptions of health through use of colour and graphical elements such as pictures or symbols ${ }^{(6,7)}$.

The global food supply has become more concentrated, with major transnational food manufacturers becoming larger and more powerful ${ }^{(8,9)}$. Researchers have accused the globalised food system, driven by large manufacturers and supermarket chains, of creating processed foods that are identical throughout the world ${ }^{(10)}$. They suggest that the extent and purpose of food processing forms the basis of a classification system for use in dietary guidance ${ }^{(11)}$. Industrially processed foods that include cosmetic or sensory additives such as colours, flavours, sweeteners, or processing aids, or undergo industrial processes which have no domestic equivalent such as extrusion, also referred to as ultra-processed foods (UPF), have been found to have higher saturated fat, sugar and sodium content compared with less processed foods ${ }^{(12,13)}$. UPF have also been described as hyper-palatable products that are attractively packaged and aggressively marketed, including making use of health statements and claims ${ }^{(12)}$.

In Australia, there is a high level of foreign ownership of food brands by transnational food manufacturers ${ }^{(14)}$. UPF are prevalent, with annual retail sales per capita of 
$200.5 \mathrm{~kg}$ in 2013, and Australia ranked sixth out of eight nations for total annual UPF sales ${ }^{(15)}$. The majority ( $\left.83 \%\right)$ of available packaged foods in New Zealand are UPF, with multiple variations of the same product common ${ }^{(16)}$. In 2012, an Australian and New Zealand survey found that less than half of packaged foods could be described as healthy using a nutrient profiling tool ${ }^{(17)}$.

In $2011-12,63 \%$ of Australian adults and $25 \%$ of children were overweight or obese, and $35 \%$ of the population's total daily energy intake came from energy-dense nutrient-poor 'discretionary foods' that are high in added sugars, fats or salt ${ }^{(18)}$. These foods are more likely to be classified as UPF. Public health professionals agree that marketing of unhealthy foods, including via packaging, plays a role (3,19-21). $^{2}$.

The Australian and New Zealand food regulatory system aims to protect public health and safety by providing sufficient information, preventing misleading information and promoting healthy food choices ${ }^{(22)}$, while supporting an internationally competitive food industry ${ }^{(23)}$. Under the system, labels on packaging can display nutrition and health benefits; for example, using statements or claims permitted by the Australia New Zealand Food Standards Code (referred to as the 'Food Code' hereafter) ${ }^{(24)}$. The Australian Government's voluntary front-of-package Health Star Rating labelling system (HSR) was launched in 2014 to assist consumers to select healthier foods ${ }^{(25,26)}$.

Regulating food marketing on product packaging, including the label, is a challenging food policy issue of public health significance ${ }^{(27)}$. Many food companies make corporate social responsibility commitments, particularly regarding safeguarding children from problems associated with food marketing ${ }^{(28)}$, and provide voluntary nutrition information on food labels in addition to the mandatory nutrition information panel ${ }^{(29)}$. It is important to understand the application of marketing statements as well as the nutrition and health claims made by manufacturers of high-market-share packaged foods and their potential impact on food choice. The aim of the present study was to objectively evaluate voluntary nutrition and health labelling, claims and marketing techniques on highmarket-share UPF in Australia for their potential impact on public health.

\section{Methods}

\section{Selection of food companies}

The global network International Network for Food and Obesity Research Monitoring and Action (INFORMAS) aims to monitor, benchmark and support actions to create healthy food environments to reduce obesity, noncommunicable diseases and their related inequalities ${ }^{(30)}$. It recommends focusing on the companies with the largest potential to impact public health nutrition when monitoring the policies and practices of the food industry ${ }^{(31)}$.
Five high-market-share manufacturers of packaged foods in Australia were identified from Nielsen's Top Brands Report 2009, specifically: Allen's, Kellogg's, Nestlé, Sanitarium and Uncle Toby's ${ }^{(32)}$. Nestlé (including the Allen's brand) had the largest share (13.9\%) of the chocolate and confectionery market in Australia ${ }^{(33)}$. Kellogg's (17.8\%) had the largest market share of breakfast cereals in Australia, and Sanitarium (15.4\%) and Nestlé (including Uncle Toby's; $7 \cdot 1 \%$ ) also had a significant share ${ }^{(34)}$. To explore the emerging trend of supermarket own brands, the widely available Woolworths Supermarkets' Macro range was also included ${ }^{(35)}$.

\section{Selection of packaged foods}

Breakfast cereals, snacks and confectionery are among the categories most commonly marketed to children ${ }^{(36,37)}$. Foods audited included all the breakfast cereals, snacks and confectionery items, and selected beverages, condiments and liquid breakfast meal replacements (referred to as 'meal replacements' hereafter) available at the time of the study from the food manufacturers. Products were identified from the companies' websites. Labelling information from the 230 packaged foods identified was collected.

\section{Data collection}

The information for the audit was gathered from the companies' or online shopping websites for Coles and Woolworths, and 'in store' at Coles and Woolworths supermarkets in Cockburn Gateway Shopping Centre in Western Australia, after obtaining permission from the store managers. The following information was collected: product name and brand, processed food group, added sugar and added fat ingredients, nutrition composition; the extent of packaging promotion to children; and nutrition labelling practices and price. Data collection was completed in September 2015.

\section{Categorisation of nutrition-related information}

The extent of food processing for all packaged foods was identified, and foods were classified using the NOVA system $^{(12)}$ to analyse the impact of these foods on public health- and diet-related outcomes. The NOVA system of classifying foods according to the extent of food processing, not nutrient content, aims to address the significance of industrial food processing to public health ${ }^{(12)}$. The term ultra-processed foods (UPF) is used to describe nutritionally poor, industrially processed foods that include cosmetic or sensory additives such as colours, flavours, sweeteners or processing aids; or undergo industrial processes which have no domestic equivalent such as extrusion $^{(12)}$. The other groups in this classification system are: unprocessed or minimally processed foods, which may be consumed by themselves; processed culinary ingredients, which are used in food preparation; and processed foods, which are relatively simple foods with few ingredients ${ }^{(12)}$. 

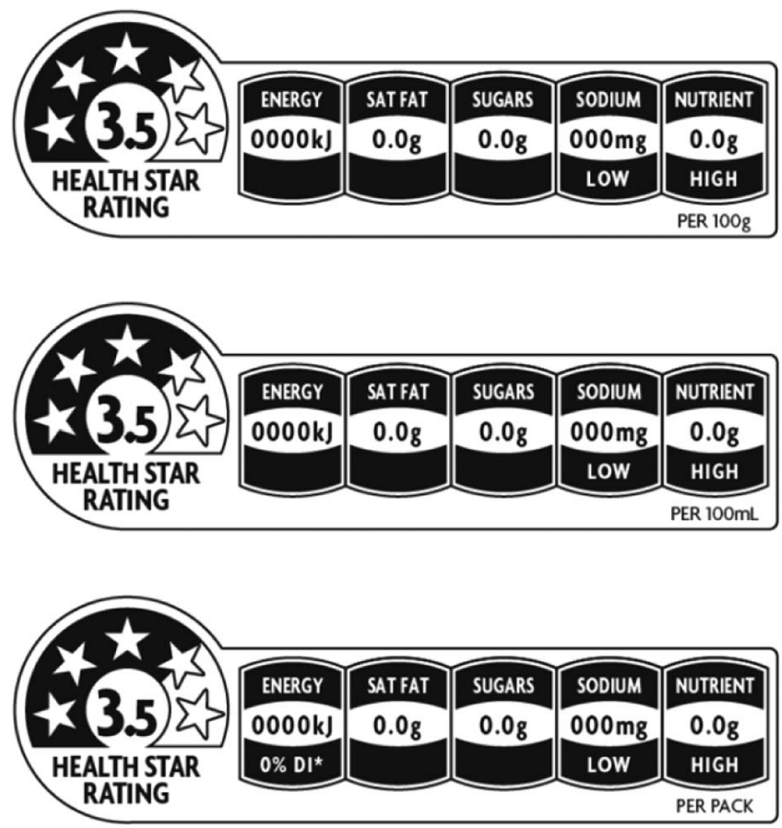

Fig. 1 Health Star Rating front-of-pack device ${ }^{(16)}$

Free sugars and fats are commonly added to $\mathrm{UPF}^{(12)}$, and the Food Code definition of added sugars ${ }^{(38)}$ and a list of commonly used names for sugars ${ }^{(39)}$ were used to guide identification of added sugars.

Guidelines for use of the voluntary HSR front-of-pack labelling device ${ }^{(40)}$ were used to assess the HSR on-pack. The HSR algorithm awards points for positive food or nutrient content (dietary fibre, protein and the proportion of fruit, vegetables, nuts and legumes) and subtracts points for negative nutrients (saturated fat, sodium, total sugars, but not added sugars), then assigns a score from $1 / 2$ star to 5 stars, with 5 stars indicating the healthiest choice ${ }^{(41)}$ (Fig. 1). The online calculator provided on the HSR website $^{(40)}$ was used to calculate the HSR for all products, using the nutrition information panel provided on the packaging. Few products included fruit, vegetables, nuts and legumes in the ingredients list; thus the calculation was based on content per 100 grams of the following: energy (kilojoules), saturated fat, sugars, sodium, dietary fibre and $\operatorname{protein}^{(41)}$.

\section{Classification of packaging information}

Packaging information was classified using the taxonomy shown in Fig. 2, based on defined nutrition information and marketing techniques identified by INFORMAS ${ }^{(42)}$ and Mayhew et $a l^{(43)}$. The analysis identified the voluntary components implemented by the food companies that could be influenced by company corporate social responsibility policies. The presence of mandatory nutrition- and health-related information (e.g. nutrition information panels) was collected but not reported as they were present for all products. Products were classified as targeting children using criteria employed by
Mehta et al. to examine packaging targeting Australian children, which stipulates a minimum of two out of a possible five attributes are present ${ }^{(3)}$ (Fig. 2).

\section{Compliance of statements and claims}

The Food Code was used to assess legal compliance of food packaging information using the criteria that are required to be met to make health and nutrition claims. Claims were classified as: (i) nutrient content; (ii) nutrient comparative; (iii) ingredient health-related; (iv) general level health; or (v) high level health ${ }^{(24,38,44)}$. Health endorsements administered by organisations such as the Heart Foundation could not be assessed for accuracy, as criteria and product accreditation status were not publicly available. The Australian Competition and Consumer Commission's food descriptors guideline to the Trade Practices Act $2006^{(45)}$, which defines deceptive and misleading representations about food and beverages, was referred to and mainly related to application of the Food Code for this data set.

Consideration was given to Clause 10 of the nutrition, health and related claims standard (Standard 1.2.7 $7^{(24)}$ ), which states that it does not prescribe the words that must be used. Clause 13 of the nutrition, health and related claims standard (Standard 1.2.7 $7^{(24)}$ ) states that nutrition content claims may be made about a property not listed in the Schedule (Schedule $4^{(38)}$ ) but the claim can only state that the food does or does not contain this property, that it contains a specified amount, or a combination of these two statements. Claims about the presence or amount of wholegrains were therefore determined to be permitted even though they were not specifically listed in Schedule 4 , and were categorised as ingredient health-related claims for the present study. The Grains \& Legumes Nutrition Council $^{\mathrm{TM}}$ in Australia has created a voluntary code of practice to encourage promotion of wholegrains on food labels ${ }^{(46)}$. Therefore, the Grains \& Legumes Nutrition Council's criteria were used for assessment of claims against voluntary standards to assess compliance with industry self-regulation.

Data were analysed using the statistical software package IBM SPSS Statistics for Windows version 24 (released 2016).

\section{Results}

\section{Level of food processing}

Most (94\%) products were classified as UPF using the NOVA system ${ }^{(12)}$ (Table 1). These 215 UPF formed the data set for analysis.

\section{Added sugars and added fats}

Most UPF products (95\%) contained added sugars (Table 1). Fourteen types of sugar were used in the products, with thirty-four different ingredient names used 


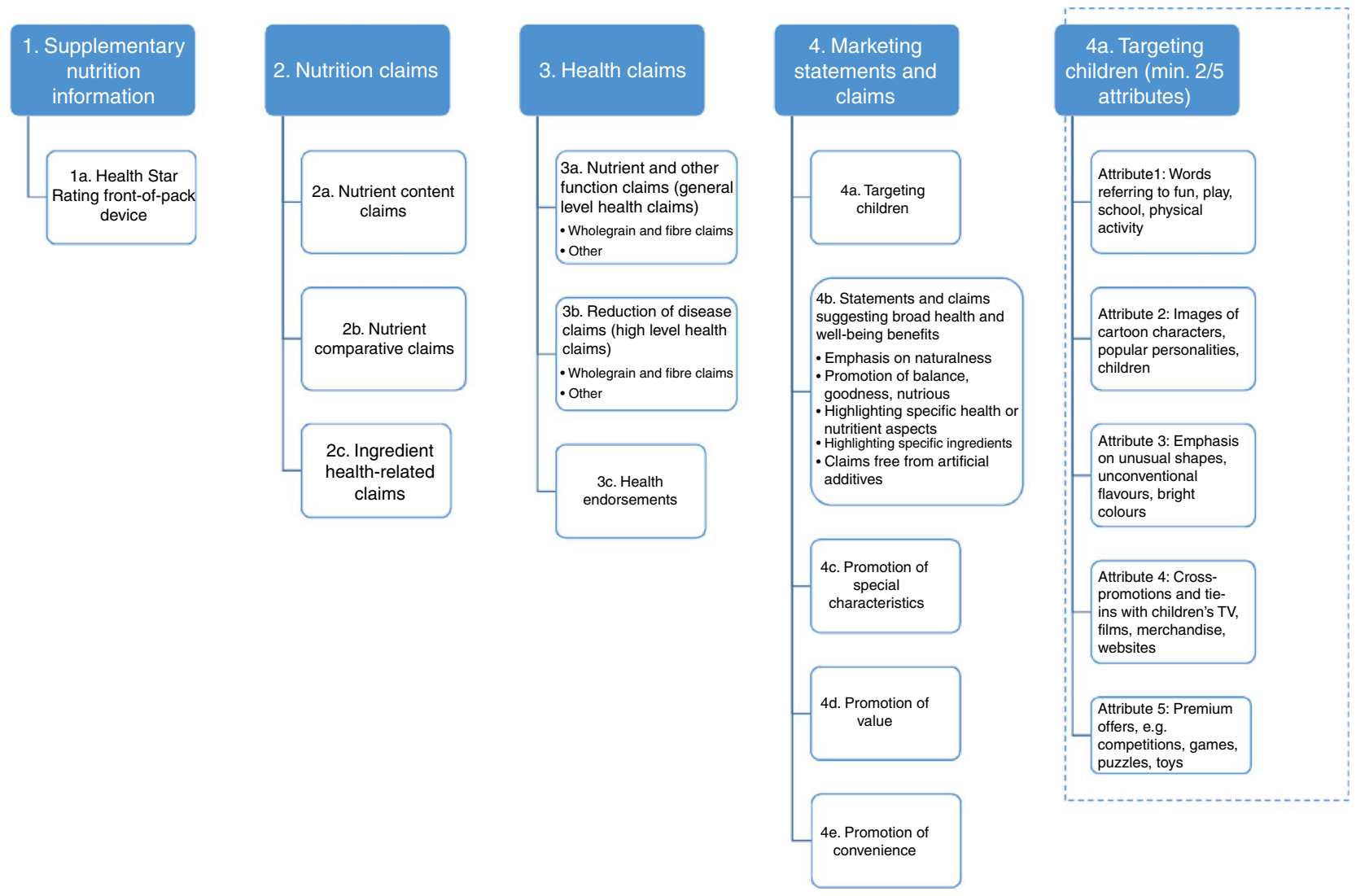

Fig. 2 Taxonomy of nutrition- and health-related packaging information*. *Adapted from the INFORMAS food labelling taxonomy ${ }^{(42)}$, Mayhew et al.'s definitions of marketing techniques promoting health and well-being ${ }^{(43)}$, and Mehta et al.'s work defining food packaging targeting children ${ }^{(3)}$ (TV, television)

(e.g. 'sugar' was also listed as 'raw sugar', 'organic raw sugar', 'organic sugar', 'cane sugar' and 'brown sugar'). The overall mean number of ingredient names used for sugar per product was 2.5 (range $0-8$ ). The mean number of ingredient names used for sugar per pack was highest for snack foods at $3 \cdot 8$ (range $0-8$ ). Over half (62\%) of products contained added fats; however, the mean number of terms used in ingredients lists was only 1.0 (range 0-3; Table 1).

\section{Classification of packaging information}

The numbers of products providing supplementary nutrition information (i.e. HSR), nutrition claims, health claims, and marketing statements or claims are shown in Table 1. Overall $55 \%$ of products had a HSR, $59 \%$ had nutrition or health claims, and $97 \%$ had selected marketing techniques. On average, each product displayed 1.5 (range 0-10) health or nutrition claims and 2.6 (range 0-5) marketing techniques on the packaging.

The mean number of health stars for all products was 2.97 HSR (range 0.5-5). Breakfast cereals, condiments and meal replacements had a mean HSR of 3.5-5.0 (Table 1) and $55 \%$ of all products achieved a HSR of 3.5-5.0.

Most (95\%) of the products with health or nutrition claims also included marketing statements highlighting broad health benefits. Of these, $87 \%$ also featured the HSR; and $82 \%$ would be described as healthy (HSR of 3.5-5.0) based on research that determined that foods with these HSR scores were more likely to be consistent with the nutritious core foods recommended by the Australian Guide to Healthy Eating (AGHE) ${ }^{(47-49)}$.

The most frequent marketing technique used was promotion of 'balance' or 'goodness' (57\%), followed by claims of being free from artificial additives (47\%) and packaging that targets children (47\%). Promotion of value or convenience were the least used marketing techniques.

Most (61\%) of the packaging targeting children featured three of the five identified marketing attributes. Fewer products designed to appeal to children featured the HSR (35\%) compared with family-oriented products (55\%).

\section{Validation of statements and claims}

Results from validation of the HSR and nutrition and health claims are summarised in Table 2. The HSR device was used on $55 \%$ of products and the calculation was correct for all products.

Nutrition claims were correct for $18 \%$ of products making this type of claim (Table 2). Few claims about fibre content complied with criteria specified in the Food Code. The minimum quantity specified in the claims criteria was 
Table 1 Packaging claims and statements present on ultra-processed foods suitable for families from four Australian manufacturers, September 2015

\begin{tabular}{|c|c|c|c|c|c|c|c|c|c|c|c|c|c|c|c|c|c|c|c|c|c|}
\hline & \multicolumn{3}{|c|}{ Breakfast cereals } & \multicolumn{3}{|c|}{ Beverages } & \multicolumn{3}{|c|}{ Condiments } & \multicolumn{3}{|c|}{ Confectionery } & \multicolumn{3}{|c|}{ Snacks } & \multicolumn{3}{|c|}{$\begin{array}{c}\text { Meal } \\
\text { replacements }\end{array}$} & \multicolumn{3}{|c|}{ All products } \\
\hline & $n$ & $\%$ & Mean & $n$ & $\%$ & Mean & $n$ & $\%$ & Mean & $n$ & $\%$ & Mean & $n$ & $\%$ & Mean & $n$ & $\%$ & Mean & $n$ & $\%$ & Mean \\
\hline \multicolumn{22}{|l|}{ NOVA classification of food processing } \\
\hline Group 1 (unprocessed) & 8 & $8 \cdot 70$ & - & 0 & 0.00 & - & 0 & 0.00 & - & 0 & 0.00 & - & 1 & 1.72 & - & 0 & 0.00 & - & 9 & 3.91 & - \\
\hline Group 2 (processed culinary ingredients) & 0 & 0.00 & - & 0 & 0.00 & - & 2 & 28.57 & - & 0 & 0.00 & - & 0 & 0.00 & - & 0 & 0.00 & - & 2 & 0.87 & - \\
\hline Group 3 (processed foods) & 2 & $2 \cdot 17$ & - & 0 & 0.00 & - & 0 & 0.00 & - & 0 & 0.00 & - & 2 & 3.45 & - & 0 & 0.00 & - & 4 & 1.74 & - \\
\hline Group 4 (ultra-processed foods) & 82 & 89.13 & - & 15 & $100 \cdot 00$ & - & 5 & 71.43 & - & 46 & $100 \cdot 00$ & - & 55 & 94.83 & - & 12 & $100 \cdot 00$ & - & 215 & 93.48 & - \\
\hline Proportion of final data set & 82 & 38.14 & - & 15 & 6.98 & - & 5 & 2.33 & - & 46 & 21.40 & - & 55 & $25 \cdot 58$ & - & 12 & $5 \cdot 58$ & - & 215 & $100 \cdot 00$ & - \\
\hline No. of products & 78 & $95 \cdot 12$ & - & 12 & $80 \cdot 00$ & - & 3 & $60 \cdot 00$ & - & 46 & $100 \cdot 00$ & - & 53 & 96.36 & - & 12 & $100 \cdot 00$ & - & 201 & 94.88 & - \\
\hline Mean sugar cont & - & - & 19.5 & - & - & $29 \cdot 6$ & - & - & $6 \cdot 8$ & - & - & 51.5 & - & - & 24.8 & - & - & $7 \cdot 1$ & - & - & $27 \cdot 4$ \\
\hline Mean no. of terms used for added sugar & - & - & 2.6 & - & - & 0.9 & - & - & 0.6 & - & - & 1.8 & - & - & 3.8 & - & - & $2 \cdot 3$ & - & - & 2.5 \\
\hline \multicolumn{22}{|l|}{ Products containing added fat } \\
\hline No. of products & 31 & 37.80 & - & 5 & 33.33 & - & 4 & 80.00 & - & 30 & $65 \cdot 22$ & - & 52 & $98 \cdot 11$ & - & 12 & $100 \cdot 00$ & - & 134 & $62 \cdot 33$ & - \\
\hline Mean fat $c$ & - & - & 4.9 & - & - & $2 \cdot 8$ & - & - & $42 \cdot 6$ & - & - & $14 \cdot 1$ & - & - & 9.7 & - & - & 1.4 & - & - & 8.6 \\
\hline Mean no. of terms used for added fat & - & - & 0.4 & - & - & 0.7 & - & - & 0.8 & - & - & 1.1 & - & - & 1.6 & - & - & $2 \cdot 0$ & - & - & 1.0 \\
\hline \multicolumn{22}{|l|}{ Australian Guide to Healthy Eating indicator } \\
\hline $\begin{array}{l}\text { kJ per serving is } \geq 600 \\
\text { 1. Supplementary nutrition information present }\end{array}$ & 39 & $47 \cdot 56$ & - & 2 & 13.33 & - & 0 & 0.00 & - & 2 & 4.35 & - & 7 & $12 \cdot 73$ & - & 12 & $100 \cdot 00$ & - & 62 & 28.84 & - \\
\hline 1a. Health Star Rating device present & 82 & $100 \cdot 00$ & - & 10 & 66.67 & - & 5 & $100 \cdot 00$ & - & 0 & 0.00 & - & 9 & $16 \cdot 36$ & - & 12 & $100 \cdot 00$ & - & 118 & 54.88 & \\
\hline Mean calculated Health Star Rating & - & - & 3.9 & - & - & $3 \cdot 2$ & - & - & 3.6 & - & - & 1.2 & - & - & $2 \cdot 6$ & - & - & 4.6 & - & - & $3 \cdot 0$ \\
\hline 2. Nutrition claims & 70 & $85 \cdot 37$ & - & 11 & 73.33 & - & 5 & $100 \cdot 00$ & - & 4 & 8.70 & - & 19 & 34.55 & - & 12 & $100 \cdot 00$ & - & 121 & $56 \cdot 28$ & - \\
\hline 2a. Nutrie & 66 & 80.49 & - & 11 & 73.33 & - & 5 & 100.00 & - & 2 & 4.35 & - & 16 & 29.09 & - & 12 & $100 \cdot 00$ & - & 112 & 52.09 & - \\
\hline 2b. Comparative nutrient claims & 5 & $6 \cdot 10$ & - & 5 & 33.33 & - & 0 & 0.00 & - & 2 & 4.35 & - & 3 & 5.45 & - & 7 & $58 \cdot 33$ & - & 22 & $10 \cdot 23$ & - \\
\hline alth-related claims & 47 & $57 \cdot 32$ & - & 0 & 0.00 & - & 0 & 0.00 & - & 0 & 0.00 & - & 4 & $7 \cdot 27$ & - & 0 & 0.00 & - & 51 & 23.72 & - \\
\hline 3. Health claims & 44 & 53.66 & - & 1 & 6.67 & - & 2 & 40.00 & - & 0 & 0.00 & - & 4 & 7.27 & - & 2 & $16 \cdot 67$ & - & 53 & 24.65 & - \\
\hline 3a. General level health claims & 16 & $19 \cdot 51$ & - & 1 & 6.67 & - & 0 & 0.00 & - & 0 & 0.00 & - & 0 & 0.00 & - & 2 & $16 \cdot 67$ & - & 19 & $8 \cdot 84$ & - \\
\hline 3b. High level health claims & 1 & 1.22 & - & 0 & 0.00 & - & 2 & 40.00 & - & 0 & 0.00 & - & 0 & 0.00 & - & 0 & 0.00 & - & 3 & 1.40 & - \\
\hline 3c. En & 37 & $45 \cdot 12$ & - & 0 & 0.00 & - & 2 & 40.00 & - & 0 & 0.00 & - & 4 & $7 \cdot 27$ & - & 0 & 0.00 & - & 43 & $20 \cdot 00$ & - \\
\hline 4. Marketing statements or claims & 79 & $96 \cdot 34$ & - & 14 & 93.33 & - & 5 & $100 \cdot 00$ & - & 44 & 95.65 & - & 55 & $100 \cdot 00$ & - & 12 & $100 \cdot 00$ & - & 209 & $97 \cdot 21$ & - \\
\hline Mear & - & - & $2 \cdot 4$ & - & - & $2 \cdot 1$ & - & - & 3.0 & - & - & $2 \cdot 8$ & - & - & $3 \cdot 1$ & - & - & $2 \cdot 3$ & - & - & $2 \cdot 6$ \\
\hline 4a. Packaging designed to appeal to children & 25 & 30.49 & - & 4 & $26 \cdot 67$ & - & 4 & 80.00 & - & 28 & 60.87 & - & 40 & $72 \cdot 73$ & - & 0 & 0.00 & - & 101 & 46.98 & - \\
\hline $\begin{array}{l}\text { Mean no. of children's marketing attributes present } \\
\text { (max. 5) }\end{array}$ & - & 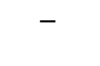 & 1.5 & - & - & $1 \cdot 3$ & - & - & $1 \cdot 8$ & - & - & $2 \cdot 0$ & - & - & $2 \cdot 2$ & - & - & 1.0 & - & - & $1 \cdot 8$ \\
\hline 4b. Statements suggesting broad health benefits & 75 & 91.46 & - & 13 & 86.67 & - & 5 & $100 \cdot 00$ & - & 44 & 95.65 & - & 49 & 89.09 & - & 12 & $100 \cdot 00$ & - & 198 & 92.09 & - \\
\hline Emphasis on naturalness & 19 & 23.17 & - & 0 & 0.00 & - & 0 & 0.00 & - & 7 & $15 \cdot 22$ & - & 7 & $12 \cdot 73$ & - & 0 & 0.00 & - & 33 & $15 \cdot 35$ & - \\
\hline Promotion of balance, goo & 43 & 52.44 & - & 5 & 33.33 & - & 0 & 0.00 & - & 42 & $91 \cdot 30$ & - & 25 & 45.45 & - & 7 & $58 \cdot 33$ & - & 122 & 56.74 & - \\
\hline th or nutrient aspects & 29 & 35.37 & - & 8 & 53.33 & - & 3 & 60.00 & - & 0 & 0.00 & - & 15 & $27 \cdot 27$ & - & 12 & $100 \cdot 00$ & - & 67 & 31.16 & - \\
\hline Highlighting specific nutrients & 30 & 36.59 & - & 1 & $6 \cdot 67$ & - & 4 & 80.00 & - & 0 & 0.00 & - & 31 & 56.36 & - & 2 & $16 \cdot 67$ & - & 68 & 31.63 & - \\
\hline Claims free from artificial additives & 26 & $31 \cdot 71$ & - & 4 & 26.67 & - & 4 & $80 \cdot 00$ & - & 32 & 69.57 & - & 34 & 61.82 & - & 0 & 0.00 & - & 100 & $46 \cdot 51$ & - \\
\hline of special characteristics & 5 & $6 \cdot 10$ & - & 9 & $60 \cdot 00$ & - & 0 & 0.00 & - & 19 & 41.30 & - & 17 & 30.91 & - & 0 & 0.00 & - & 50 & $23 \cdot 26$ & - \\
\hline 4d. Promotion of value & 1 & 1.22 & - & 0 & 0.00 & - & 0 & 0.00 & - & 0 & 0.00 & - & 0 & 0.00 & - & 0 & 0.00 & - & 1 & 0.47 & - \\
\hline 4e. Promotion of convenience & 15 & $18 \cdot 29$ & - & 0 & 0.00 & - & 0 & 0.00 & - & 1 & $2 \cdot 17$ & - & 0 & 0.00 & - & 7 & $58 \cdot 33$ & - & 23 & $10 \cdot 70$ & - \\
\hline
\end{tabular}


Table 2 Accuracy of packaging information present on ultra-processed foods suitable for families from four Australian manufacturers, September 2015

\begin{tabular}{|c|c|c|c|}
\hline & $\begin{array}{l}\text { No. of products } \\
\text { making the claim }\end{array}$ & $\begin{array}{c}\text { No. of products } \\
\text { with all claims correct }\end{array}$ & $\begin{array}{l}\% \text { of products with } \\
\text { all claims correct }\end{array}$ \\
\hline \multicolumn{4}{|l|}{ 1. Supplementary nutrition information } \\
\hline 1a. Health Star Rating device & 118 & 118 & $100 \cdot 0$ \\
\hline 2. Nutrition claims present & 118 & 21 & $17 \cdot 8$ \\
\hline 2a. Nutrient content claims & 113 & 21 & $18 \cdot 6$ \\
\hline Contains/source/good source of fibre & 44 & 5 & 11.4 \\
\hline High/very high/excellent source of fibre & 24 & 3 & 12.5 \\
\hline Other nutrient content claim $†$ & 95 & 21 & $22 \cdot 1$ \\
\hline 2b. Comparative nutrient claims & 22 & 6 & $27 \cdot 3$ \\
\hline 2c. Ingredient health-related claims & 52 & 38 & 73.1 \\
\hline Contains/source/amount of wholegrains & 40 & 38 & 95.0 \\
\hline High/good source of wholegrains & 7 & 0 & 0.0 \\
\hline Very high/excellent source of wholegrains & 5 & 0 & 0.0 \\
\hline Contribution to daily wholegrains target & 10 & 8 & 80.0 \\
\hline 3. Health claims present & 19 & 15 & 78.9 \\
\hline 3a. General level health claims & 17 & 13 & 76.5 \\
\hline General level claim: fibre or wholegrain & 3 & 3 & $100 \cdot 0$ \\
\hline General level claim: other & 16 & 12 & $75 \cdot 0$ \\
\hline 3b. High level health claims & 3 & 3 & $100 \cdot 0$ \\
\hline High level claim: fibre or wholegrain & 1 & 1 & $100 \cdot 0$ \\
\hline High level claim: other & 2 & 2 & $100 \cdot 0$ \\
\hline 3c. Endorsements & 43 & $\mathrm{n} / \mathrm{a}$ & $\mathrm{n} / \mathrm{a}$ \\
\hline
\end{tabular}

n/a, not applicable.

*Each item of packaging can include multiple classifications of nutrition and health claims.

†An additional $16.3 \%$ of claims could not be assessed for accuracy as micronutrient content data were not collected.

often not met. Claims about presence of wholegrains were appropriately specified by $73 \%$ of products, and substantiated with the wholegrain ingredients identified in ingredients lists. However, the criteria stipulated by the Grains \& Legumes Nutrition Council industry group for high or very high source of wholegrains claims were not met by any of the products making these claims.

Other nutrient claims were common (44\%) with some relating to micronutrient content; $22 \%$ of these claims met Food Code criteria (Table 2). Unspecific wording was the most common issue, such as 'contains B vitamins' without giving details of the individual $\mathrm{B}$ vitamins.

Only $27 \%$ of comparative nutrient claims met Food Code criteria (Table 2). Again, wording was not specific enough; for example, ' $40 \%$ less sugar when compared to leading kids snacks' without specifying the products being compared.

Health claims were present on $25 \%$ of products and were correct for $79 \%$ (Table 2). The most frequent health statement was through a third-party endorsement logo such as the Heart Foundation Tick (20\%). There were much higher levels of compliance for general level and high level claims than for nutrition claims, with most meeting criteria $(77 \%$ of general level, $100 \%$ of high level). Two general level health claims were unable to be assessed as they referred to health benefits for nutrients that were not included on packaging as part of the nutrition information panel.

\section{Discussion}

The current study identified packaging information present on UPF promoting nutrition and health, and classified it using a taxonomy based on previous work in this area ${ }^{(3,42,43)}$. The presence of added sugars and fats, and ingredient labelling practices were investigated. Use of the HSR, nutrition and health claims, and marketing techniques was also investigated. Prevalence of nutrition and health attributes on packaging specifically targeting children was of particular interest.

\section{Use of the taxonomy for classifying nutrition and bealth statements and claims}

The taxonomy of nutrition and health statements and claims adapted for use in the present study provided a framework for classifying the information present on high-market-share UPF in Australia. The novel aspect of our study is the integration of a food labelling taxonomy from INFORMAS ${ }^{(42)}$, marketing techniques promoting health and well-being ${ }^{(43)}$, and food packaging targeting children ${ }^{(3)}$ to describe the nature and extent of this information.

\section{Added sugars and fats}

The present study identified a high prevalence of added sugars in UPF. This is not surprising, as Australian and US population dietary surveys ${ }^{(50,51)}$ have found UPF contribute most of the added sugars consumed. An independent review of Australian food labelling recommended that changes are made to the way added fats and added sugars are identified in ingredients lists, to improve transparency:

'Where sugars, fats or vegetable oils are added as separate ingredients in a food, the terms "added sugars" and "added fats" and/or "added vegetable 
oils" be used in the ingredient list as the generic term, followed by a bracketed list (e.g., added sugars (fructose, glucose syrup, honey), added fats (palm oil, milk fat) or added vegetable oils (sunflower oil, palm oil)).' (Recommendation 12, p. $9^{(52)}$ )

Multiple terms for added sugars were commonly used on packaging, which makes deciphering ingredients lists difficult for consumers. Splitting sugar into component ingredients places them lower in the list of ingredients, obscuring the ranking that sugar would otherwise have. Our findings support the recommendation for increased transparency of added sugars on packaging ${ }^{(52)}$. A separate added sugars line on nutrition information panels, as has recently been introduced in the $\mathrm{USA}^{(53)}$, should also be considered. Interestingly, despite the recommendation for similar action on added fats ${ }^{(52)}$, the present study found that they were more clearly labelled.

The majority of Australian adults and children consume too much added sugar, typically consumed as $\mathrm{UPF}^{(54)}$. Governments ${ }^{(55)}$, public health researchers ${ }^{(56)}$, campaigners $^{(57)}$ and even supermarket chains ${ }^{(58)}$ have called for measures to control or reduce the amount of added sugars present in processed foods. Clearly identifying the amount of added sugars present in UPF is a priority to assist food regulation to protect public health by informing consumers and to underpin health promotion interventions. For example, the LiveLighter ${ }^{(}$social marketing campaign aims to educate the population about the amount of sugar present in soft drinks ${ }^{(59)}$ and public health advocates are calling for a sugar tax on soft drinks in Australia ${ }^{(60)}$.

\section{Classification of packaging information}

UPF have been described as hyper-palatable products that are attractively packaged and aggressively marketed, including making use of health statements and claims ${ }^{(12)}$. The present study has demonstrated the accuracy of the definition when applied to a sample of high-market-share UPF in Australia. More than half of the UPF packaging in our study featured nutrition or health claims, and almost all of the packaging utilised marketing techniques which related to nutrition and health. In addition, each pack typically displayed multiple claims and marketing techniques, demonstrating the extent to which this sort of information is used. Analysis from Canada, the UK, the USA and Brazil has demonstrated the poor nutritional quality of $\mathrm{UPF}^{(61-63)}$, so this high prevalence of nutrition- and health-related statements and claims on packaging is concerning.

Over half of the products selected for the current study featured a HSR on the packaging, although monitoring surveys at the time reported that only $3 \%$ of products carried a HSR ${ }^{(64)}$. Breakfast cereal manufacturers adopted the HSR faster than other categories ${ }^{(64)}$, which is not surprising given that Sanitarium, a breakfast cereal manufacturer, and Woolworths Supermarkets were the first public commercial supporters of the scheme ${ }^{(64,65)}$.
The present study demonstrates the complexity of attempting to consolidate different principles for defining and identifying healthy food choices, for example based on nutrient profiling (HSR), food group categorisation (AGHE) or processing (NOVA). The HSR of most UPF products that featured nutrition or health claims in the current study was 3.5-5.0; previous research suggested that foods rated 3.5 stars or above were consistent with the nutritious core foods in the AGHE food selection guide $^{(47-49)}$. The level of HSR, and the presence of nutrition and health claims, on UPF is at odds with their typically poor nutritional quality ${ }^{(61)}$. Another Australian study found similar anomalies; for example, bread or pasta, classified as UPF due to their level of processing, are considered nutritious core foods in the $\mathrm{AGHE}^{(66)}$.

A recent review of the relationship between changes in the food system and the global nutrition transition highlights the challenges and importance of describing and categorising foods to measure the health implications of the ongoing changes in the food supply ${ }^{(67)}$. In 2015 Poti et al. extended the NOVA system by further describing food processing and including 'convenience', dividing UPF into two groups: 'highly processed' ingredients and 'highly processed' stand-alone foods ${ }^{(13)}$. Resolution of discrepancies in recommended dietary patterns such as those of the AGHE and individual foods recommended by food processing systems such as NOVA, as well as frontof-pack labelling advice including HSR and nutrition and health claims, is needed to clarify dietary advice to consumers. Further research to develop an understanding of the effect of multiple nutrition and health claims and statements, combined with the HSR, on consumer food selection is also suggested.

Most products that featured nutrition or health claims also carried messages that were classified as marketing techniques. Marketing techniques designed to make products appealing to potential consumers do not receive the same level of regulatory scrutiny as claims. A wide range of marketing techniques was evident in the present study, with most statements suggesting broad health benefits. These marketing techniques were applied to packaging in all categories surveyed, including confectionery and snacks. This is consistent with recent research conducted across sixteen countries which found that $87 \%$ of all snack food packaging featured claims emphasising general health, wellbeing or naturalness ${ }^{(43)}$. Unregulated statements that products are 'free from' artificial additives such as colours and flavours, or promote 'balance' or 'goodness', often mislead consumers into thinking these products are more healthful than they actually are ${ }^{(43)}$ or that their inclusion in a healthy diet is permitted or normal ${ }^{(9)}$. These are common marketing techniques used by UPF manufacturers to broaden their appeal and make frequent consumption acceptable ${ }^{(12)}$. Our findings suggest that urgent action is needed to prevent marketing practices that potentially mislead consumers into thinking these unhealthy products are healthy. 
The current study adds to the existing literature documenting the high level of inappropriate marketing to children present on packaging of UPF in Australia ${ }^{(3)}$. Most products that were designed to appeal to children featured three of the five marketing attributes previously identified $^{(3)}$. Voluntary action by the food industry to restrict marketing of food to children was initiated by the Australian Food and Grocery Council in $2008^{(68)}$. However, the Responsible Children's Marketing Initiative ${ }^{(68)}$ focuses on encouraging responsible advertising and to date has not addressed marketing at the point of sale, including packaging. The voluntary approach has also not yet proved to be effective in reformulating products targeting children to improve their nutritional quality ${ }^{(69,70)}$. Most parents express concern about the level of food marketing to children ${ }^{(71)}$. Therefore, more public policies are needed to assist parents to identify healthy packaged foods. These policies should address the accuracy and quality of nutritional information provided on UPF.

Given the prevalence of marketing techniques identified in our study, and the challenges in regulating packaging on products targeting children ${ }^{(27)}$, alternative strategies to assist consumers to select healthy packaged foods could be investigated. For example, the supermarket-wide Guiding Stars system uses an algorithm to assess both positive and negative nutrient content and has been adopted by five supermarket chains in the USA ${ }^{(72)}$. Guiding Stars aimed to overcome consumers' inability to make sense of the plethora of information present on food packaging by providing a simple guide on the shelf-edge tag along with the price $^{(73)}$. Evaluation shows the Guiding Stars shelf-edge labelling of healthy foods was effective in assisting consumers to purchase more healthy foods overall ${ }^{(74)}$. Australian public policy to assist consumers to select healthy packaged foods should consider such strategies that can be applied across all UPF available in supermarkets, particularly if voluntary uptake of HSR does not prove effective in assisting consumers to select healthy foods.

\section{Validation of statements and claims}

The present study was unique in that it validated the HSR and nutrition and health claims present on UPF against the Food Code $^{(24,29,38,44)}$ and other criteria ${ }^{(41,46)}$. Findings showed that the HSR and high level health claims used were typically accurate. However, there were many issues identified for nutrition claims, and lower levels of accuracy for general level health claims.

Claims on breakfast cereals about dietary fibre or wholegrains content were present on some packaging; however, many were not accurate because the minimum quantity specified in the claims criteria in the Food Code was not met ${ }^{(38)}$. This finding is surprising, as the packaging included in the current study was from high-market-share food manufacturers who would be expected to meet the criteria specified in the Food Code. In addition, claims about products being a high or very high source of wholegrains not only failed to follow the Food Code ${ }^{(29)}$, but also failed to adhere to the industry's voluntary code ${ }^{(46)}$. This indicates the importance of monitoring and surveillance of packaging information applied to UPF, with financial penalties for lack of adherence to regulations and guidelines.

UPF failing to provide accurate nutrition claims on packaging included wording that was not specific enough, typically when products declared the presence of added vitamins and minerals, or made comparisons of nutrient content with other products. However, for the information to be helpful to consumers it needed to include details that were not provided. These deceptive and misleading practices should be addressed in public policies to provide consumer-friendly nutrition labelling that is easy to understand and addresses public health concerns ${ }^{(75)}$.

\section{Limitations}

The present study has a number of strengths and limitations. Challenges were faced in determining the accuracy of claims for various reasons. Clause 10 of the nutrition, health and related claims standard (Standard 1.2.7 $7^{(24)}$ ) states that it does not prescribe the words that must be used. Therefore, assessment of the accuracy of these statements made on packaging was open to interpretation, and other researchers or enforcement authorities may differ in their views.

The study's findings are likely generalisable to breakfast cereals, snacks and confectionery in the Australian food supply, and given the globalised supply of multinational UPF, may be applicable to other countries ${ }^{(10)}$. Only 215 UPF products in five food categories were audited; however, it is likely that the same issues apply across other food categories or with other food manufacturers. Therefore, we recommend further research to classify packaging information from a broader range of product categories. Testing the accuracy of nutrition and health claims on a larger sample of products would also assist in identifying the scale of the problems identified in the current study. Packaging information including the food industry's Daily Intake Guide thumbnail ${ }^{(76)}$ and micronutrients present in nutrition information panels were not collected in the present study. Future research should include this information so that full assessment of supplementary nutrition information (i.e. HSR for the present study) and nutrition and health claims can be undertaken.

Strengths of the study include the detailed taxonomy applied to classify packaging information, which includes nutrition and health claims, marketing techniques and classification of products designed to appeal to children, as well as validating these nutrition and health statements and claims.

\section{Conclusions}

The taxonomy of nutrition and health statements and claims proved effective in describing the nature and extent of information present on packaging of high-market-share 
UPF in Australia. Based on the findings in the present study, UPF were typically attractively packaged with labels that incorporated multiple marketing techniques, and extensively utilised nutrition and health statements and claims, despite many products containing added sugars or being rated a less healthy choice. The proportion of inappropriate or inaccurate statements and claims is concerning, particularly on UPF packaging designed to appeal to children. Public policies to assist parents to select healthy packaged foods need to address the accuracy and quality of nutritional information provided on packaged foods, reducing deceptive marketing practices. Recommendations include: clearly identifying the amount of added sugars present in UPF by adding a separate added sugars line on nutrition information panels similar to the USA; conducting further research to ensure the HSR correctly identifies the nutritional quality of UPF; conducting further research to build the evidence for the role of level of food processing in the selection of healthy dietary patterns; resolving discrepancies in recommended dietary patterns (e.g. AGHE) and individual foods recommended by different systems such as NOVA and front-of-pack labelling advice (e.g. HSR); and consider wider application of a modified HSR across all food products to more accurately advise consumers on how to select foods for a healthy dietary pattern. Monitoring and surveillance of compliance of packaging information applied to UPF with current regulations is also important.

\section{Acknowledgements}

Acknowledgments: The authors would like to thank Denise Chew Ching Li for assistance with data collection. Financial support: Healthway, the Western Australian Health Promotion Foundation, funded Curtin University to assist the translation of research into practice through the 5-year Food Law, Policy and Communications to Improve Public Health Project. C.E.P is the recipient of a Health Promotion Research Scholarship from Healthway. The funder had no role in study design, data collection and analysis, decision to publish, or preparation of the manuscript. Conflict of interest: None. Authorship: C.E.P. and C.M.P. are responsible for formulation of the research question and designing the study. C.E.P is responsible for analysing the data and writing the article. All authors discussed the results and implications and commented on the manuscript at all stages. Ethics of human subject participation: Not applicable.

\section{References}

1. Kotler P \& Armstrong G (2015) Products, services, and brands: building customer value. Principles of Marketing, 16th ed., p. 264. Boston, MA: Pearson.

2. Abrams KM, Evans C \& Duff BRL (2015) Ignorance is bliss. How parents of preschool children make sense of front-ofpackage visuals and claims on food. Appetite 87, 20-29.
3. Mehta K, Phillips C, Ward P et al. (2012) Marketing foods to children through product packaging: prolific, unhealthy and misleading. Public Health Nutr 15, 1763-1770.

4. TNS BMRB Research (2016) Understanding NI Consumer Needs Around Food Labelling. Belfast: Food Standards Agency; available at http://www.food.gov.uk/northernireland/news-updates/news/2016/15424/understanding-niconsumer-needs-around-food-labelling

5. Enax L, Weber B, Ahlers M et al. (2015) Food packaging cues influence taste perception and increase effort provision for a recommended snack product in children. Front Psychol 6, 882.

6. Purnhagen K, van Herpen E \& van Kleef E (2016) The potential use of visual packaging elements as nudges. In Nudging - Possibilities, Limitations and Applications in European Law and Economics, pp. 197-216 [K Mathis and A Tor, editors]. Cham: Springer International Publishing.

7. Hamlin RP (2016) The consumer testing of food package graphic design. Br Food J 118, 379-395.

8. Tillotson JE (2004) America's obesity: conflicting public policies, industrial economic development, and unintended human consequences. Annu Rev Nutr 24, 617-643.

9. Moodie R, Stuckler D, Monteiro C et al. (2013) Profits and pandemics: prevention of harmful effects of tobacco, alcohol, and ultra-processed food and drink industries. Lancet 381, 670-679.

10. Monteiro CA, Moubarac JC, Cannon G et al. (2013) Ultraprocessed products are becoming dominant in the global food system. Obes Rev 14, 21-28.

11. Monteiro CA, Cannon G, Moubarac J-C et al. (2015) Dietary guidelines to nourish humanity and the planet in the twenty-first century. A blueprint from Brazil. Public Health Nutr 18, 2311-2322.

12. Monteiro CA, Cannon G, Levy R et al. (2016) NOVA. The star shines bright. World Nutr 7, 28-38.

13. Poti JM, Mendez MA, Ng SW et al. (2015) Is the degree of food processing and convenience linked with the nutritional quality of foods purchased by US households? Am J Clin Nutr 101, 1251-1262.

14. Department of Agriculture Fisheries and Forestry (2012) FOODmap: An Analysis of the Australian Food Supply Chain. Canberra: Commonwealth of Australia; available at http://www.agriculture.gov.au/ag-farm-food/food/publications/ foodmap-a-comparative-analysis

15. Pan American Health Organization (2015) Ultra-Processed Food and Drink Products in Latin America: Trends, Impact on Obesity, Policy Implications. Washington, DC: Pan American Health Organization; available at http://iris.paho. org/xmlui/bitstream/handle/123456789/7699/978927511864__ eng.pdf? sequence $=5 \&$ isAllowed $=\mathrm{y} \& u a=1$

16. Luiten CM, Steenhuis IH, Eyles H et al. (2016) Ultraprocessed foods have the worst nutrient profile, yet they are the most available packaged products in a sample of New Zealand supermarkets. Public Health Nutr 19, 530-538.

17. Ni Mhurchu C, Brown R, Jiang Y et al. (2016) Nutrient profile of 23596 packaged supermarket foods and nonalcoholic beverages in Australia and New Zealand. Public Health Nutr 19, 401-408.

18. Australian Bureau of Statistics (2014) Australian Health Survey: Nutrition First Results - Foods and Nutrients, 2011-12. Catalogue no. 4364.0.55.007. Canberra: ABS; available at http://www.abs.gov.au/ausstats/abs@.nsf/mf/ 4364.0.55.007? OpenDocument; archived at http://www. webcitation.org/6WtZcTlgl

19. Hawkes C, Jewell J \& Allen K (2013) A food policy package for healthy diets and the prevention of obesity and dietrelated non-communicable diseases: the NOURISHING framework. Obes Rev 14, 159-168.

20. Kraak VI \& Story M (2015) An accountability evaluation for the industry's responsible use of brand mascots and 
licensed media characters to market a healthy diet to American children. Obes Rev 16, 433-453.

21. Harris JL, Pomeranz JL, Lobstein T et al. (2009) A crisis in the marketplace: how food marketing contributes to childhood obesity and what can be done. Annu Rev Public Health 30 , 211-225.

22. Australia and New Zealand Ministerial Forum on Food Regulation (2013) Overarching Strategic Statement for the Food Regulatory System. Canberra: Department of Health; available at http://foodregulation.gov.au/internet/fr/publishing.nsf/Content/ foodsecretariat-stategic-statement

23. Department of Agriculture and Water Resources, Australian Government (2016) Agriculture, farming and food/Food. http://www.agriculture.gov.au/ag-farm-food/food (accessed June 2016).

24. Food Standards Australia New Zealand (2016) Australia New Zealand Food Standards Code - Standard 1.2.7 Nutrition, health and related claims. https://www.legislation. gov.au/Series/F2015L00394 (accessed March 2016).

25. Cancer Council Australia (2014) Position statement - Front of Pack Food Labelling. Sydney: Cancer Council Australia; available at http://wiki.cancer.org.au/policy/Position_ statement_-_Front_of_Pack_Food_Labelling

26. Department of Health (2015) Front-of-Pack Labelling Updates. Canberra: Department of Health; available at http://foodregulation.gov.au/internet/fr/publishing.nsf/ Content/front-of-pack-labelling-1

27. Hawkes C (2010) Food packaging: the medium is the message. Public Health Nutr 13, 297-299.

28. Crane A \& Kazmi B (2010) Business and children: mapping impacts, managing responsibilities. J Bus Ethics 91, 567-586.

29. Food Standards Australia New Zealand (2016) Australia New Zealand Food Standards Code - Standard 1.2.8 Nutrition Information Requirements. https://www.legislation. gov.au/Series/F2015L00395 (accessed March 2016).

30. Swinburn B, Sacks G, Vandevijvere S et al. (2013) INFORMAS (International Network for Food and Obesity/noncommunicable diseases Research, Monitoring and Action Support): overview and key principles. Obes Rev 14, 1-12.

31. Sacks G, Swinburn B, Kraak V et al. (2013) A proposed approach to monitor private-sector policies and practices related to food environments, obesity and noncommunicable disease prevention. Obes Rev 14, 38-48.

32. Nielsen (2010) Top brands report 2009. In Retail World, vol. February 15 2010, pp. 15-22. Australia: National Association of Retail Grocers of Australia.

33. Cloutman N (2016) Chocolate and Confectionery Manufacturing in Australia. Industry Report C1182. Melbourne: IBISWorld; available at https://www.ibisworld.com.au/ industry-trends/market-research-reports/manufacturing/foodproduct/chocolate-confectionery-manufacturing.html

34. Johnson S (2016) Cereal, Pasta and Baking Mix Manufacturing in Australia. Industry Report C1162. Melbourne: IBISWorld; available at https://www.ibisworld.com.au/industrytrends/market-research-reports/manufacturing/food-product/ cereal-pasta-baking-mix-manufacturing.html

35. Woolworths (2016) Macro Range. Australia: Woolworths; available at https://www.woolworths.com.au/Shop/Discover/ our-brands/macro

36. Cairns G, Angus K, Hastings G et al. (2013) Systematic reviews of the evidence on the nature, extent and effects of food marketing to children. A retrospective summary. Appetite 62, 209-215.

37. Ni Mhurchu C, Mackenzie T \& Vandevijvere S (2016) Protecting New Zealand children from exposure to the marketing of unhealthy foods and drinks: a comparison of three nutrient profiling systems to classify foods. $N Z \mathrm{Med} J$ 129, 41-53.

38. Food Standards Australia New Zealand (2016) Australia New Zealand Food Standards Code - Schedule 4 - Nutrition, health and related claims. https://www.legislation.gov.au/ Details/F2016C00189 (accessed March 2016).

39. Clemons R (2015) Added sugars on food labels. https://www.choice.com.au/food-and-drink/nutrition/foodlabelling/articles/added-sugar-on-food-labels-070815\#names (accessed May 2016).

40. Department of Health (2014) Health Star Rating: Calculator and Artwork. Canberra: Commonwealth of Australia; available at http://www.healthstarrating.gov.au/internet/ healthstarrating/publishing.nsf/content/Calculator

41. Department of Health (2015) Health Star Rating System. Canberra: Commonwealth of Australia; available at http:// healthstarrating.gov.au/internet/healthstarrating/publishing. nsf/Content/About-health-stars

42. Rayner M, Wood A, Lawrence M et al. (2013) Monitoring the health-related labelling of foods and non-alcoholic beverages in retail settings. Obes Rev 14, 70-81.

43. Mayhew AJ, Lock K, Kelishadi R et al. (2016) Nutrition labelling, marketing techniques, nutrition claims and health claims on chip and biscuit packages from sixteen countries. Public Health Nutr 19, 998-1007.

44. Food Standards Australia New Zealand (2016) Australia New Zealand Food Standards Code - Schedule 5 - Nutrient profiling scoring method. https://www.legislation.gov.au/ Details/F2016C00190 (accessed March 2016).

45. Australian Competition and Consumer Commission (2006) Food and Beverage Industry. Food Descriptors Guideline to the Trade Practices Act. Dickson: Commonwealth of Australia; available at https://www.accc.gov.au/system/files/ Food\%20descriptors\%20guidelines.pdf

46. Grains \& Legumes Nutrition Council ${ }^{\mathrm{TM}}$ (2015) Code of Practice for Whole Grain Ingredient Content Claims. Australia: GLNC; available at http://www.glnc.org.au/ codeofpractice/code-of-practice/

47. Dunford E, Cobcroft M, Thomas M et al. (2015) Technical Report: Alignment of NSW Health Food Provision Policy with the Health Star Ratings System. North Sydney: NSW Ministry of Health; available at http://www.health.nsw.gov. au/heal/Publications/health-star-rating-system.pdf

48. National Health and Medical Research Council (2013) Australian Dietary Guidelines. Canberra: Commonwealth of Australia; available at http://www.eatforhealth.gov.au/ sites/default/files/files/the_guidelines/n55_australian_dietary_ guidelines.pdf; archived at http://www.webcitation.org/6Wt XXmGt4

49. Carrad AM, Louie JCY, Yeatman HR et al. (2016) A nutrient profiling assessment of packaged foods using two star-based front-of-pack labels. Public Health Nutr 19, 2165-2174.

50. Australian Bureau of Statistics (2016) Australian Health Survey: Consumption of Added Sugars. Australia 2011-12. Catalogue no. 4364.0.55.011. Canberra: Commonwealth of Australia; available at http://www.ausstats.abs.gov.au/ ausstats/subscriber.nsf/0/84F8A7C39FBBDDEDCA257FA10023 08ED/\$File/4364.0.55.011_2011-12.pdf

51. Martínez Steele E, Baraldi LG, Louzada MLdC et al. (2016) Ultra-processed foods and added sugars in the US diet: evidence from a nationally representative crosssectional study. BMJ Open 6, e009892.

52. Blewett N, Goddard N, Pettigrew S et al. (2011) Labelling Logic - the Final Report of the Review of Food Labelling Law and Policy. Canberra: Commonwealth of Australia; available at https://web.archive.org/web/20170311180952/ http://www.foodlabellingreview.gov.au/internet/foodlabel ling/publishing.nsf/content/labelling-logic

53. Food and Drug Administration (2016) The New and Improved Nutrition Facts Label - Key Changes. Washington, DC: US FDA; available at http://www.fda.gov/downloads/ Food/IngredientsPackagingLabeling/LabelingNutrition/ UCM511646.pdf 
54. Lei L, Rangan A, Flood VM et al. (2016) Dietary intake and food sources of added sugar in the Australian population. Br J Nutr 115, 868-877.

55. Rayner M, Scarborough P \& Briggs A (2015) Public Health England's report on sugar reduction. BMJ 351, h609.

56. Saksena R \& Scherdel L (2015) Prioritisation of sugar to tackle obesity. Lancet Glob Health 3, e447.

57. Siegle L (2015) Just what the doctor ordered: Jamie Oliver declares war on sugar. The Guardian, 30 August. http://www.theguardian.com/commentisfree/2015/aug/30/ jamie-oliver-fizzy-drinks-sugar-rush-campaign-welcome (accessed August 2015).

58. Donnelly L (2016) Force supermarkets to cut the sugar content in our products, says Sainsbury chief. The Telegraph, 19 February. http://www.telegraph.co.uk/journalists/laura-donnelly/ 12165556/Force-us-to-cut-the-sugar-content-in-our-productssays-Sainsbury-chief.html (accessed February 2016).

59. LiveLighter (2016) Facts About Sugary Drinks. Australia: Cancer Council of Western Australia; available at https:// livelighter.com.au/The-Facts/About-Sugary-Drinks

60. Sacks G, Martin J \& Veerman L (2016) Australian sugary drinks tax could prevent thousands of heart attacks and strokes and save 1,600 lives. The Conversation, 13 April. http://theconversation.com/australian-sugary-drinks-tax-couldprevent-thousands-of-heart-attacks-and-strokes-and-save-1-600lives-56439 (accessed September 2016).

61. Moubarac J-C, Martins APB, Claro RM et al. (2013) Consumption of ultra-processed foods and likely impact on human health. Evidence from Canada. Public Health Nutr 16, 2240-2248.

62. Martínez Steele E, Popkin BM, Swinburn B et al. (2017) The share of ultra-processed foods and the overall nutritional quality of diets in the US: evidence from a nationally representative cross-sectional study. Popul Health Metr 15, 6.

63. Moreira PVL, Baraldi LG, Moubarac J-C et al. (2015) Comparing different policy scenarios to reduce the consumption of ultra-processed foods in UK: impact on cardiovascular disease mortality using a modelling approach. PLoS One 10, e0118353.

64. Heart Foundation (2016) Report on the Monitoring of the Implementation of the Health Star Rating System Year 1. Australia: Commonwealth Department of Health; available at http://www.healthstarrating.gov.au/internet/ healthstarrating/publishing.nsf/Content/monitoring
65. Bainbridge A (2014) Health Star Rating System: Sanitarium and Woolworths become first major supporters of system. $A B C$ News, 27 June; available at http://www.abc.net. au/news/2014-06-27/sanitarium-woolworths-supports-healthstar-rating-system $/ 5555060$

66. O'Halloran SA, Lacy KE, Grimes CA et al. (2017) A novel processed food classification system applied to Australian food composition databases. J Hum Nutr Diet (Epublication ahead of print version).

67. Popkin BM (2017) Relationship between shifts in food system dynamics and acceleration of the global nutrition transition. Nutr Rev 75, 73-82.

68. Australian Food and Grocery Council (2014) Responsible Children's Marketing Initiative. Canberra: Australian Food and Grocery Council; available at https://www.afgc.org.au/ our-expertise/health-nutrition-and-scientific-affairs/advertis ing-to-children/

69. Savio S, Mehta K, Udell T et al. (2013) A survey of the reformulation of Australian child-oriented food products. BMC Public Health 13, 836.

70. Meloncelli NJL, Pelly FE \& Cooper SL (2016) Nutritional quality of a selection of children's packaged food available in Australia. Nutr Diet 73, 88-94.

71. Kelly B, Chapman K, Hardy LL et al. (2009) Parental awareness and attitudes of food marketing to children: a community attitudes survey of parents in New South Wales, Australia. J Paediatr Child Health $\mathbf{4 5}$, 493-497.

72. Guiding Stars Licensing Company (2016) Our partners. http://guidingstars.com/partners/ (accessed June 2016).

73. Fischer LM, Sutherland LA, Kaley LA et al. (2011) Development and implementation of the guiding stars nutrition guidance program. Am J Health Promot 26, e55-e63.

74. Sutherland LA, Kaley LA \& Fischer L (2010) Guiding Stars: the effect of a nutrition navigation program on consumer purchases at the supermarket. Am J Clin Nutr 91, issue 4, 1090S-1094S.

75. Hawkes C, Smith TG, Jewell J et al. (2015) Smart food policies for obesity prevention. Lancet 385, 2410-2421.

76. Australian Food and Grocery Council (2016) Daily Intake Labelling. Canberra: Australian Food and Grocery Council; available at https://www.afgc.org.au/our-expertise/healthnutrition-and-scientific-affairs/afgcbestpracticeguides/ 